\title{
Conselheiros midiáticos: o "Caderno Equilíbrio" da Folha de São Paulo e suas ponderações na formação do indivíduo saudável
}

\author{
Ivan Marcelo Gomes* \\ Alexandre Fernandez Vaz** \\ Selvino José Assmann***
}

\begin{abstract}
Resumo: $O$ artigo analisa conselhos para a obtenção da qualidade de vida oferecidos em um veículo de imprensa. Assim, apresenta o caderno Equilíbrio da Folha de São Paulo privilegiando sua proposta editorial, os temas e textos publicados por sua equipe e, ainda, a fala dos leitores no caderno. Num primeiro momento, será apresentada a forma com que este suplemento se constitui. Num segundo momento, busca-se analisar o conteúdo do Equilíbrio em função de categorias construídas a partir do material analisado referente a seis meses de publicações. Por fim, serão tecidas reflexões sobre a atuação deste dispositivo midiático na formação de bioidentidades.
\end{abstract}

Palavras-chave: Conselheiros. Bioidentidades. Qualidade de vida.

\section{UMA DESCRIÇÃO DO CADERNO: SUA PROPOSTA, SEU LAYOUT E SEUS TEMAS}

O Equilíbrio, suplemento do jornal Folha de São Paulo desde em maio de 2000, circula as quintas-feiras. O caderno é feito pelos seguintes profissionais: uma editora, três repórteres, fotógrafos, diagramadores, artistas gráficos e repórteres free-lancers (que

*Doutor em Ciências Humanas pela Universidade Federal de Santa Catarina. Professor Adjunto do CEFD/UFES. Docente do Programa de Pós-Graduação em Educação Física da UFES. Email: ivanmgomes@hotmail.com

**Doutor em Ciências Humanas e Sociais pela Universidade de Hannover (Alemanha). Docente dos Programas de Pós-Graduação em Educação e Interdisciplinar em Ciências Humanas da UFSC. Pesquisador do CNPq. E-mail: alexfvaz@uol.com.br

***Doutor em Filosofia pela Pontifícia Università Lateranense (Itália). Docente dos Programas de Pós-Graduação Interdisciplinar em Ciências Humanas e em Filosofia da UFSC. E-mail: selvinoa@terra.com.br 
colaboram com reportagens isoladas $)^{1}$. Equilíbrio apresenta reportagens sobre qualidade de vida relacionadas com diferentes temáticas e segundo informa uma repórter, ${ }^{2}$

\begin{abstract}
É realizada uma reunião de pauta semanal na qual os repórteres apresentam sugestões de temas a serem abordados. A escolha é feita de acordo com critérios como atualidade, relevância e importância para a vida do leitor. No Equilíbrio, cobrimos assuntos relacionados a saúde e bem-estar (medicina, nutrição, fitness, massagens etc.). Tentamos enfatizar a prevenção e as iniciativas que abordem saúde, e não apenas doença.
\end{abstract}

Com doze páginas em formato tablóide, ou, às vezes, com quatro a mais de anúncios, o suplemento procura atingir um público amplo: "homens e mulheres, principalmente a partir dos vinte anos. Por isso, há matérias sobre mulheres, terceira idade, jovens, atletas, crianças (para pais), etc."'3 dividindo-se, geralmente, em nove seções, algumas não fixas.

A matéria de capa, com título e figura que lhe recobre toda a extensão, ocupa um espaço extenso, entre as páginas 6 e 9. A página 2 tem seções fixas: a coluna "outras idéias", "correio / pergunte aqui" e ainda um espaço para charge. "Outras idéias" caracteriza-se como um texto em que autores ${ }^{4}$ abordam dilemas ou pequenos tormentos cotidianos enfrentados pelos indivíduos, propondo aos leitores reflexões sobre como vivem e se aquelas formas de viver ali tratadas não seriam prejudiciais a sua qualidade de vida. As charges retratam

\footnotetext{
Conforme informações prestadas por uma das repórteres do suplemento no dia 17 de janeiro de 2007. Vale destacar, também, que a análise será restrita aos vinte e cinco números publicados entre o período de 05 de outubro de 2006 até 29 de março de 2007, procurando compreender a estrutura do Equilíbrio e verificar quais são os assuntos que mais se repetem e como são abordados.

IInformação obtida conforme nota anterior.

${ }^{3}$ Segundo a mesma repórter do caderno "não há pesquisas regulares" sobre o público atingido pelo Equilíbrio. Ela completa que "A [pesquisa] realizada no ano passado [2006], por exemplo, mostra que esse público amplo é atingido pelo caderno".

${ }^{4}$ Quatro autores revezam-se na coluna: Michael Kepp (jornalista), Anna Veronica Mautner (psicanalista), Dulce Critelli (terapeuta existencial, filósofa e professora universitária) e Wilson Jacob Filho (médico e professor universitário).
}

Movimento, Porto Alegre, v. 16, n. 04, p. 117-134, outubro/dezembro de 2010. 
de forma humorada tais dilemas. A coluna lateral, destinada aos espaços do "correio" e do "pergunte aqui", responde, através de especialistas que trazem informações específicas, a partir de questões enviadas pelos leitores.

A página 3 possui um espaço fixo denominado "ingrediente". Essa seção aborda um alimento em cada número, enfocando suas características "saudáveis"5. "Ingrediente" apresenta as reportagens sempre no mesmo padrão, priorizando o suporte de especialistas no que diz respeito às informações técnicas, históricas e nutricionais dos alimentos.

Entre as páginas 4 e 9 existe uma circularidade nos temas abordados. Essas páginas apresentam uma estrutura mais flexível e colunas que não são publicadas semanalmente ${ }^{6}$. Os textos apresentam alguns aspectos que se mantêm constantes, como a recorrência a especialistas na abordagem dos temas e os cuidados com o corpo e a qualidade de vida.

Na página 5, também identificamos, a cada quinze dias, a coluna "Neurociência", assinada pela neurocientista Suzana HerculanoHouzel. A seção apresenta uma tentativa de aproximação do leitor com pesquisas científicas, por meio de uma linguagem acessível e com a inserção de exemplos e problemas cotidianos.

As últimas páginas do caderno Equilíbrio apresentam uma estrutura fixa. Na página 10 localiza-se o "Dia-a-dia", que comporta as seções "Compare", "Na prateleira", "Em casa" e um espaço para divulgação de livros. Na seção "compare" são indicados três alimentos com descrições nutricionais subsidiadas por uma fonte especializada. Destacam-se as dicas sobre a quantidade calórica de alimentos e ressalvas se são eles saudáveis ou não. A seção "Na prateleira" apresenta breves informações sobre produtos lançados no mercado com indicações de uso e preços. Geralmente, são exibidos dois

${ }^{5}$ Quase a totalidade das matérias foi realizada por Rachel Botelho, nutricionista e professora universitária.

${ }^{6}$ Os autores dos textos dividem-se entre repórteres do Equilíbrio, colaboradores e textos traduzidos. As diferentes autorias e temáticas não representaram textos com enfoques distintos, demonstrando uma coerência na linha editorial do caderno.

Movimento, Porto Alegre, v. 16, n. 04, p. 117-134, outubro/dezembro de 2010. 
produtos relacionados ao bem-estar, como, por exemplo, artigos alimentícios, cosméticos, estilizados, entre outros. A seção "Em casa" disponibiliza dicas sobre aspectos cotidianos domiciliares, com o respaldo de um especialista. São diversos assuntos tratados, desde a conservação de alimentos até cuidados com colchões. Os livros divulgados nesta página também estão direcionados para ampliação do repertório dos leitores vinculado aos objetivos do caderno. Os conteúdos dos livros são bastante diversos e não apresentam necessariamente relação com as temáticas abordadas naquele número do suplemento.

Na página 11, a seção se denomina "Poucas e boas" e destinase a breves notícias, como divulgação de campanhas públicas, palestras, cursos e pesquisas científicas. De forma geral, apresenta informações sobre saúde e doenças, com suporte especializado. Por fim, na página 12, encontra-se o espaço denominado "S.O.S. Família", com textos assinados pela psicóloga Rosely Sayão. A seção geralmente prioriza polêmicas do cotidiano familiar e dicas para enfrentamento desses conflitos. Também existe um espaço para opiniões dos leitores, chamado "bate-papo". Nele encontramos críticas a textos antes publicados, ou à posição da autora, bem como elogios ou mesmo testemunhos de leitores que mostram grande identificação com o que leram, como um deles que certa vez bradava: "continue nos orientando" (21/12/06).

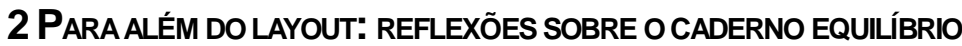

Neste tópico, analisamos, a partir de algumas categorias por nós elaboradas, os conselhos apresentados no caderno. São elas: vida equilibrada, confiança especializada, reflexividade ativa. Essas categorias articulam-se em duas frentes com o propósito de fornecer subsídios e conselhos ao leitor por meio de especialistas sobre sua saúde e o seu bem-estar. Esta busca não é priorizada no espaço público, mas, predominantemente, no espaço privado. Por isso, denominamos os espaços de ação individual da seguinte maneira: o

Movimento, Porto Alegre, v. 16, n. 04, p. 117-134, outubro/dezembro de 2010. 
"eu-corpo" e o "eu-casa". O "eu-corpo" refere-se ao campo de ação vinculado aos cuidados corporais e o "eu-casa", evidentemente, vinculado aos cuidados da casa que é, de acordo com os conselhos especializados, um campo que permitirá a constituição do indivíduo saudável. Tais frentes não são declaradas pelo Caderno, mas as identificamos, ao longo das análises, permeando diversas seções do Equilíbrio.

As categorias referidas representam ações a serem realizadas em função dos conselhos oferecidos pelos especialistas para que os indivíduos possam alcançar a desejada qualidade de vida ${ }^{7}$. A vida equilibrada estimula os indivíduos a manter o "bom senso" frente aos excessos da atual modernidade. Confiança especializada reforça a necessidade de recorrer ao serviço dos sistemas peritos para fortalecer a segurança perante as ações cotidianas. A categoria "reflexividade ativa" aponta para a necessidade da ação em função do conhecimento adquirido.

Por meio dessas categorias de análise, podemos ilustrar como os temas se equilibram no caderno. As diferentes seções do Equilíbrio transitam entre essas noções, ao mesmo tempo em que permitem mapear os focos da ação (eu-corpo, eu-casa). Exporemos o "equilíbrio do caderno" por meio dessas categorias.

\section{A VIDA EQUILIBRADA}

A vida equilibrada expõe conselhos e saberes que enfatizam a necessidade de se evitar os excessos presentes no cotidiano, sejam eles tecnológicos, eletrônicos, cosméticos, nutricionais, sonoros, corporais ou até mesmo em relação à luxúria. Estes aspectos podem ser percebidos em diferentes seções do caderno. Anna Veronica Mautner apela para a necessidade de resistência frente ao aparato tecnológico: "Minhas plantas constituem meu contraponto à

${ }^{7}$ Aqui, seguimos, não exaustivamente, algumas noções sobre análise temática, elaboradas por Laurence Bardin (1977). De maneira mais específica, nos aproximamos deste autor na forma em que apresenta as "atitudes valorizadas e rejeitadas" em uma determinada ação (BARDIN, 1977, p. 77-78).

Movimento, Porto Alegre, v. 16, n. 04, p. 117-134, outubro/dezembro de 2010. 
modernidade que me soterra [...] Para a nova geração, não basta admirar o milagre da natureza, é preciso apontar que nós também, como ela, podemos resistir." (p.12, 21/12/06).

$\mathrm{O}$ estresse causado pelas atribulações dos deveres cotidianos também entra no rol dos excessos a serem evitados. Suzana Herculano-Houzel salienta a necessidade de estar no controle de algumas situações cotidianas, pois "reduz diretamente a resposta ao estresse e favorece a saúde"; mas como nem tudo está sob nosso controle, a autora recomenda: "A sabedoria está no meio-termo [...]" (p.5, 12/10/06).

A necessidade de "bom senso" em relação aos exageros estéticos está presente no engodo que pode ocorrer nos tratamentos luxuosos para o corpo oferecidos em spas. Os custos desses tratamentos não refletem os benefícios prometidos, como indica a reportagem de Iara Biderman, na seção "bem-estar" (p.6-9, 25/01/ 07). Este alerta também representa uma tensão presente no Caderno, visto que os cuidados corporais, tão almejados pelos leitores, se enquadram nessa promessa dos spas, mas também, nas descobertas nutritivas dos alimentos, tecnologias, terapias, etc. Ou seja, no Equilíbrio convivem as ressalvas sobre as promessas presentes em anúncios estéticos, como também, o estímulo a busca por novas sensações e prazeres corporais (BAUMAN, 1999). Ao mesmo tempo, esse alerta ilustra a atenção e uma espécie de "educação sobre o corpo", pois tanto o prazer anunciado pelos spas, quanto o alerta apresentado pela reportagem, representam uma aprendizagem e um cultivo da escuta do próprio corpo (BOLTANSKI, 2007).

O trecho de uma reportagem assinada por Tatiana Diniz, dentro da "temática saúde", sobre cólicas incapacitantes, resume a noção de uma "vida equilibrada": "Encarar a vida com menos pressão, comer bem, praticar exercícios, cultivar o bem-estar. Esses são os ingredientes finais da receita para afastar as complicações da doença e manter o corpo sob controle." (DINIZ, p. 8, 15/03/07).

Movimento, Porto Alegre, v. 16, n. 04, p. 117-134, outubro/dezembro de 2010. 


\section{A CONFIANÇA ESPECIALIZADA}

O caderno Equilíbrio respalda seu conteúdo em saberes especializados. Esta característica dos sistemas peritos é utilizada em todas as seções do caderno, oferecendo uma espécie de garantia, mesmo em um contexto aberto a ambivalências e incertezas. $\mathrm{O}$ saber especializado, sempre em constante renovação em função dos novos conhecimentos elaborados cientificamente e de novas tecnologias, ou em função dos estímulos mercadológicos, parece se constituir em uma miragem de fortaleza para os indivíduos em um mundo que se apresenta movediço (GIDDENS, 1991; FRIDMAN, 2000). A confiança especializada expressa no Equilíbrio valoriza o saber e a procura por especialistas, ou, nos termos de Zygmunt Bauman, o serviço dos conselheiros. Para esse autor:

[...] Os conselheiros [...] cuidam de nunca pisar fora da área fechada do privado [...] Os conselhos que os conselheiros oferecem se referem à políticavida, não à Política com P maiúsculo; eles se referem ao que as pessoas aconselhadas podem fazer elas mesmas e para si próprias, cada uma para si - não ao que podem realizar em conjunto para cada uma delas, se unirem forças. (BAUMAN, 2001, p.77).

No mesmo sentido, a confiança especializada rejeita e alerta para os perigos de atividades sem orientação profissional especializada, promessas absurdas e generalização de resultados, quando ainda não há um consenso entre os especialistas. Tal característica também pode ser captada em diferentes seções do caderno, mas privilegiaremos a fala dos leitores, observada em espaços a eles destinados no caderno, principalmente, as seções "pergunte aqui", "correio" e "bate-papo".

Antes, porém, veremos um exemplo que sintetiza a categoria. As reportagens sempre estão subsidiadas pelo suporte de especialistas na defesa ou crítica de um determinado elemento que constitui a busca por qualidade de vida. Naquela assinada por de Amarílis Lage, aparece o seguinte e recorrente alerta: "A dica para

Movimento, Porto Alegre, v. 16, n. 04, p. 117-134, outubro/dezembro de 2010. 
se encontrar nesse mar de opções é procurar um bom profissional, mais do que um método específico [...]" (LAGE, p. 8, 23/11/06).

Os leitores do caderno expressam a "confiança especializada" pelas questões ou elogios apresentados em todas as edições pesquisadas. No "pergunte aqui", sempre uma questão de um leitor é solucionada por um especialista. Seja qual for o questionamento, a resposta segue sempre o mesmo formato: "Segundo o médico Cláudio Kemp, chefe de disciplina de mastologia da Unifesp [...]" (p.2, 15/ 02/07). As ações realizadas sem orientação profissional são vistas com alarde. Em reportagem de Flávia Mantovani (01/02/07) sobre os riscos da prática de atividades físicas sem orientação profissional, observamos a recorrência a vários especialistas para que o leitor fique atento aos perigos a que está sujeito. Especialistas apelam e indicam outros especialistas para que a prática individual não enfrente contratempos.

As seções "correio" e "bate-papo" apresentam, geralmente, elogios às reportagens ou aos colunistas, que transitam ao redor da confiança e da reflexão proporcionada aos leitores. Vejamos alguns: "[...] Quando li o Equilíbrio, fiquei impressionada [...] Vou me informar a respeito" (p.2, 08/03/07); e por fim, "[...] você escreve para todas nós mulheres. É bom saber que, mesmo distante, você, escritora, psicóloga, etc., é nossa alma gêmea e sente como nós sentimos [...]" (22/03/07). Essa última leitora citada inicia seu depoimento de forma bastante elucidativa para os propósitos do caderno: "Lendo, aproveito e me equilibro."

Mantendo a vida equilibrada e com a confiança depositada nos especialistas, existe ainda um passo decisivo na formação do indivíduo saudável: agir. Ou como diz uma leitora em relação a um dos especialistas/conselheiros do Equilíbrio: "[...] É para se pensar e discutir. Valeu pela leitura e por despertar os sentidos." (p. 12, 26/ 10/06).

Movimento, Porto Alegre, v. 16, n. 04, p. 117-134, outubro/dezembro de 2010. 


\section{A reflexividade ativa}

A reflexividade ativa engloba no suplemento as características vinculadas à ação. Tal categoria seria a culminância do processo, ou seja, quando o indivíduo, com a posse do conhecimento especializado, coloca em prática a construção da sua qualidade de vida. Uma das características marcantes do Caderno enquadra-se nesta categoria. Estamos nos referindo às técnicas e sugestões apresentadas para 0 indivíduo enfrentar situações e dilemas cotidianos. Elas podem ser oferecidas de forma direta ou, então, por meio de opções, para que o leitor compare e escolha. Identificamos conselhos para as mais variadas situações: técnicas/dicas para contrabalancear o barulho das cidades, para solução de problemas caseiros, para questões estéticas, nutritivas e de saúde e para resolução de problemas no relacionamento familiar.

Percebe-se que a necessidade de realização de escolhas é uma característica marcante da reflexividade ativa. Desde a "escolha da escola", título de um dos textos de Rosely Sayão (p.12, 26/10), no qual exorta à tomada de decisão dos pais, até a opção de frutas melhoradas geneticamente que ampliam o repertório do consumidor, conforme é apresentado na reportagem de Tatiana Diniz (p.5, 22/ 02/07). Exemplo emblemático da necessidade de escolher encontrase na seção "compare": o indivíduo/leitor é chamado a uma reflexão na qual deve comparar entre três produtos oferecidos e orientados por uma fonte especializada que o previne sobre os aspectos saudáveis envolvidos em seu processo decisório. Em outras palavras, esta seção reflete as inúmeras decisões a que os indivíduos são convocados em defesa de seu corpo.

Aspecto interessante relacionado às escolhas é o de que esta noção ilustra também a ambivalência presente no caderno. Ao mesmo tempo em que se exalta a necessidade de uma reflexividade ativa e se enaltece o aumento de opções para as escolhas, também existe o questionamento desta necessidade. Rosely Sayão escreve e reconhece a necessidade de inúmeras escolhas no cotidiano, mas

Movimento, Porto Alegre, v. 16, n. 04, p. 117-134, outubro/dezembro de 2010. 
diz que "o problema é que escolher tem sido cansativo", em virtude da imposição de ter em demasia que escolher (p. 12, 01/02/07).

Saberes e técnicas divergentes convivem na sociedade de consumo "ao gosto do freguês", ou mais especificamente, em relação ao nosso foco de análise: "ao gosto do leitor". Embora prevaleça o imperativo da qualidade de vida (saúde, bem-estar), neste suplemento os saberes transmitidos não são necessariamente lineares. A busca pela "alimentação saudável", que aparece de forma constante no Caderno, foi alvo de críticas no próprio Equilíbrio em uma reportagem feita por Denise Mota na qual foi abordado o lançamento do livro "The gospel of food", do sociólogo Barry Glassner, que argumenta que "[...] tudo o que você acha que sabe sobre comida está errado." (MOTA, p. 6, 01/03/07).

A responsabilidade e a tomada de decisões também constituem características da reflexividade ativa, pois reforçam a atitude individual como um aspecto decisivo para a melhoria do bem-estar e da saúde. Uma saída apresentada pelo Equilíbrio para que nossas ações surtam o efeito desejado passa necessariamente por uma outra ação: a mudança de valores contra os excessos cotidianos (CRITELLI, p.2, 04/01/07).

Embora o tom crítico apareça em outros momentos do caderno, esse não é o padrão. Melhor dizendo, essa não é a tônica do suplemento no que se refere à ruptura que ele propõe. A mudança de valor que é mais acentuada no Equilíbrio é a mudança individual em relação aos estilos de vida com ênfase nos aspectos do bemestar e da saúde.

Como dissemos anteriormente, o imperativo da qualidade de vida reina no Equilíbrio. A atividade física aparece como um dos ícones da questão. Ela contribui para defender o corpo [do leitor] de um dos vilões que ameaçam a qualidade de vida: a obesidade. Isso pode ser ilustrado pela reportagem de Iara Biderman, intitulada "emagreça no verão". Conforme salienta um especialista ouvido pela reportagem: "A idéia é perder peso sem perder o prazer - esse é outro fator que contribui para

Movimento, Porto Alegre, v. 16, n. 04, p. 117-134, outubro/dezembro de 2010. 
o sucesso dos programas de emagrecimento no verão. E vale bastante para a atividade física." (p. 5, 15/02/07).

Mas o marco desta categoria, aquela em que o indivíduo sempre deve se apresentar disposto ao chamamento dos especialistas na defesa de sua qualidade de vida, foi publicado em uma das capas do caderno: "cumpra o que promete" (21/12/06). A seção "ano novo" esmiúça esta exortação ao apresentar "7 promessas de ano novo": "1) lidar melhor com o estresse [...] 2) sair do sedentarismo [...] 3) emagrecer [...] 4) parar de fumar [... 5) ser mais organizado [...] 6) dormir melhor [...] 7) passar protetor solar [...]" (p.6-9, 21/12/06). Novamente, a ação estimulada no Equilíbrio refere-se à monitoração e à disposição para a mudança dos indivíduos no que tange ao seu estilo de vida. Essas sete promessas traçam o perfil do indivíduo saudável que o caderno preconiza.

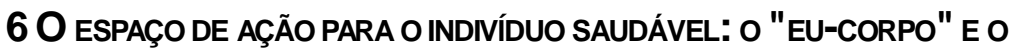 "EU-CASA"}

Esses espaços de ação são indicados no Caderno ao mapear as "mudanças simples no dia-a-dia" que o indivíduo pode executar na consecução de seu bem-estar e da sua saúde. As articulações entre cuidados do corpo e cuidados da casa ampliarão a garantia, como enfatizam os especialistas/conselheiros do suplemento, da qualidade de vida tão almejada pelos leitores do Equilíbrio. Os temas apresentados nos tópicos anteriores ilustram tais focos de atenção que o indivíduo deve possuir no enfrentamento. Seja na "organização da casa" ou na "prática de atividades físicas", será o indivíduo o responsável pelas escolhas, em função da confiança e dos saberes disponibilizados pelos especialistas e pela tomada de iniciativa. Vale ressaltar, novamente, que a grande maioria dos conselhos para esta batalha afirma que se trata de uma luta individual e, mais ainda, amplamente vivenciada na relação com o próprio corpo.

Anthony Giddens aborda esta questão como constituinte dos mecanismos auto-identitários presentes nas instituições modernas.

Movimento, Porto Alegre, v. 16, n. 04, p. 117-134, outubro/dezembro de 2010. 
Para o autor, a "confiança especializada" dos leitores do Equilíbrio está vinculada a uma forma precoce de segurança ontológica. Segundo ele:

\begin{abstract}
Nas situações a que chamo de modernidade 'alta' ou 'tardia' - nosso mundo de hoje -, o eu, como os contextos institucionais mais amplos em que existe, tem que ser construído reflexivamente. Mas essa tarefa deve ser realizada em meio a uma enigmática diversidade de opções e possibilidades (GIDDENS, 2002, p. 10-11).
\end{abstract}

O Equilíbrio fornece, na abordagem giddensiana, conhecimentos filtrados por especialistas que são característicos da estruturação das auto-identidades, entendidas, para este autor, como "um empreendimento reflexivamente organizado." (GIDDENS, 2002, p. 12). Como visto no Equilíbrio, este sintoma moderno recai sobre o indivíduo. Giddens propõe que o estilo de vida decorrente desta pluralidade de escolhas seja compreendido para além de um consumismo superficial, definindo o termo da seguinte forma:

\footnotetext{
[...] Os estilos de vida são práticas rotinizadas, as rotinas incorporadas em hábitos de vestir, comer, modos de agir e lugares preferidos de encontrar os outros; mas as rotinas seguidas estão reflexivamente abertas à mudança à luz da natureza móvel da auto-identidade (GIDDENS, 2002, p.80).
}

Giddens não esquece que existe uma padronização corporal impulsionada pela dinamização do consumo, como mostra o seguinte trecho: "[...] a seleção ou criação de estilos de vida é influenciada por pressões de grupo e pela visibilidade de modelos, assim como pelas circunstâncias socioeconômicas" (2002, p.81). Mas este autor opta por valorizar as tomadas de decisão vinculadas à sensação de segurança ontológica proporcionada por tais empreendimentos reflexivos: "[...] Seria muita miopia ver esse fenômeno apenas em termos dos novos ideais de aparência corporal (como a esbelteza e a juventude), ou apenas como produzido pela influência mercantilizada da propaganda" (GIDDENS, 2002, p. 98).

Movimento, Porto Alegre, v. 16, n. 04, p. 117-134, outubro/dezembro de 2010. 
Para além da miopia denunciada por Giddens, podemos perceber que uma análise menos glamourosa da reflexividade e mais contida nos apelos de uma determinada formulação sobre a saúde, contribui também para um olhar atento sobre a contemporaneidade. A análise que estamos propondo referente ao Equilíbrio foca o modelo de indivíduo saudável que perpassa as suas edições semanais. O Caderno apresenta um determinado alcance social, mas, indiferentemente de sua projeção social, observamos, nos tópicos anteriores, que os leitores do Caderno apresentam uma relação reflexiva e também de esforço em relação aos conselhos, dicas e informações divulgadas.

Parece que encontramos aí um ponto frágil na argumentação giddensiana, ao relativizar a pressão exercida pelos modelos de estilo de vida, veiculados pela mídia na sociedade de consumo. O estilo de vida saudável oferecido pelo caderno Equilíbrio é mais um dos inúmeros espaços de divulgação com o suporte de especialistas que reforçam determinados imperativos, neste caso, o imperativo e o padrão do que é ser saudável. A sensação de segurança oferecida pelo modelo de vida equilibrada no Caderno reforça um determinado modelo e que, mesmo em constante revisão, sugere uma vida mais prazerosa para aqueles que se envolverem com essa tarefa.

Nesse sentido, o Equilíbrio da Folha de São Paulo pode ser entendido como um dispositivo de controle sobre a vida. A "reflexividade ativa", entendida em nossa análise como a culminância da proposta de educação do indivíduo saudável, pode ser interpretada a partir da reflexão de Ortega sobre as bioidentidades. Assim:

[...] As modernas asceses corporais, as bioasceses, reproduzem no foco subjetivo as regras de biossociabilidade, enfatizando-se os procedimentos de cuidados corporais, médicos, higiênicos e estéticos na construção de identidades pessoais, das bioidentidades (ORTEGA, 2004, p.15).

Ortega reforça esta discussão ao apresentar a "autoperitagem" como uma característica fundamental das bioidentidades. Assim, é potencializado por meio do discurso do risco, implicando, nas palavras

Movimento, Porto Alegre, v. 16, n. 04, p. 117-134, outubro/dezembro de 2010. 
de Ortega (2003, p.64-5), na "[...] constituição de um indivíduo responsável que orienta suas escolhas comportamentais e estilos de vida para a procura da saúde e do corpo perfeito e o desvio aos riscos". Mais adiante o autor complementa: "[...] nas modernas bioasceses e tecnologias do self, o corpo obtém um novo valor. $\mathrm{Na}$ sua materialidade sofre um desinvestimento simbólico: já não é o corpo a base do cuidado de si; agora o eu existe só para cuidar do corpo, está a seu serviço." (ORTEGA, 2003, p.69).

A formação das bioidentidades, descritas por Francisco Ortega, por meio de vários dispositivos, agrega um elemento interessante à noção de conselheiros desenvolvida por Zygmunt Bauman. Essa última noção é fundamental para a constatação desenvolvida em relação ao Caderno aqui analisado: a privatização da ambivalência corporal reforçada por um dispositivo midiático.

\section{CONSIDERAÇõES SOBRE O EQUILÍBRIO}

O Equilíbrio apresenta a responsabilidade individual de "ficar atento" aos conselhos especializados sem "cair" nos exageros da vida contemporânea. Em outras palavras, uma "vida equilibrada". Algumas questões/contradições se apresentam: como ser equilibrado perante tantas informações e dicas? As informações e os conflitos entre especialistas não reforçam os exageros da vida cotidiana (saudável)?

Embora exista uma perspectiva geral na proposta do Caderno, puderam ser observados inúmeros conflitos entre especialistas nas reportagens ou, em alguns momentos, entre seções. Mas a proposta do suplemento da Folha de São Paulo é uma entre tantas outras para a vida saudável. Paralela à segurança ontológica frisada por Giddens, existe uma incerteza perante os novos conselhos gerados e que se articula com os incessantes desejos criados para o consumidor. Mais ainda, a ênfase na boa vida restrita à esfera privada impulsiona os leitores do caderno ao exame incansável sobre si mesmo, aspecto que aparece no suplemento como uma espécie de "auto-exame" sobre o "auto-exame" sugerido aos indivíduos.

Movimento, Porto Alegre, v. 16, n. 04, p. 117-134, outubro/dezembro de 2010. 
Nesta perspectiva, o discurso normalizador proposto pelo Caderno contribui para o estabelecimento de condutas consideradas corretas e que subjugam ações e indivíduos que não se enquadram nessas posições. A vida equilibrada almeja uma maior disposição e a ampliação dos prazeres. Parece que a "vida equilibrada" convive de forma paradoxal com alguns dos "novos vícios" descritos por Umberto Galimberti (2003). Segundo o autor italiano, os novos vícios não se apresentam como uma característica da personalidade, mas sim, são visualizados como tendências coletivas às quais os indivíduos não podem se opor de maneira eficaz sob pena da exclusão social (GALIMBERTI, 2003, p.14). O consumismo é apresentado como um deles, ao prometer aos indivíduos, por meio da incessante destruição dos objetos, a garantia de identidade, status social, exercício da liberdade e bem-estar (idem, 2003, p.67). O discurso normalizador sobre a liberação corporal presente no consumismo está atrelado ao controle. Desta maneira, o corpo é apreendido como o equivalente universal no espetáculo das mercadorias (GALIMBERTI, 2003a, p. 403).

A sociedade de consumidores generaliza os novos vícios com sua impessoalidade, como afirma Galimberti. Ao mesmo tempo, ela reafirma a responsabilidade individual atualizando e ressignificando os vícios capitais caracteristicamente pessoais. Desta forma, novos e antigos vícios transitam na atualidade, com suas respectivas conseqüências. Conforme adverte Bauman (1999, p.88): "[...] A maneira como a sociedade atual molda seus membros é ditada primeiro e acima de tudo pelo dever de desempenhar o papel de consumidor $[\ldots] "$.

A questão aqui não é a de menosprezar as informações fornecidas pelo Caderno, pois existem conhecimentos úteis para os indivíduos em seu cotidiano. Para além de tal aspecto, nossa análise propõe a discussão de que esse formato traz consigo um valor que reafirma a responsabilidade individual no campo de ação privado. Ao mesmo tempo, o Caderno está imerso no caos da sociedade de consumo e seus incessantes saberes sobre o que é a vida saudável.

Mas o tom crítico, como dito anteriormente, não está ausente

Movimento, Porto Alegre, v. 16, n. 04, p. 117-134, outubro/dezembro de 2010. 
no Caderno. As críticas sobre a "cultura de consumo", por exemplo, na seção "outras idéias", ajustam-se à autocrítica característica do dinamismo moderno. Equilíbrio, como um suplemento midiático, estimula a necessidade da realização de escolhas para uma vida saudável, algumas das quais não disponíveis (em relação à aquisição) para todos os consumidores. Os preços indicados nos produtos divulgados ou nas matérias são bastante variados neste suplemento. Preços mais acessíveis a parcelas mais abrangentes da população e valores altos restritos a grupos mais restritos. Mesmo com tais discrepâncias, entendemos que o endividamento generalizado permite certa mobilidade dos consumidores, ainda que não sejam tão aptos para aquisição de produtos, especialmente quando se trata do embelezamento e do bem-estar corporal.

A busca pela qualidade de vida, proposta no Caderno, pretende atingir um público amplo, mas as ferramentas disponibilizadas para este enfrentamento exercido individualmente são bem distintas. Isto não significa que os leitores aptos para realizar escolhas não estão inseridos em outro tormento moderno: a busca constante por novas informações especializadas que garantam a felicidade.

Por fim, frisamos que a forma com que as categorias foram desenvolvidas e as reflexões por elas proporcionadas contribuem para uma determinada perspectiva de análise do Caderno. Desta maneira, este modelo explicativo oferece o rumo de como este processo colabora para a responsabilidade individual na construção da qualidade de vida. Assim, o suplemento da Folha de São Paulo é visualizado como um dispositivo para a educação do indivíduo saudável. Esta abordagem fortifica um tipo de análise na qual os conselheiros (do Equilíbrio) sempre se remetem à esfera privada e, ainda, a ênfase de que a responsabilidade de colocar em prática o conselho é do aconselhado. Este último aspecto tem que ser ponderado, em virtude de que o caderno também apresenta estas ressalvas em alguns momentos. Mas, no geral, o que se coloca é a necessidade de cultivar um novo estilo de vida. Um estilo de vida equilibrado.

Movimento, Porto Alegre, v. 16, n. 04, p. 117-134, outubro/dezembro de 2010. 
Media advisors: the section "equlíbrio" of folha de são paulo newspaper and its considerations for the formation of the healthy individual

Abstract: This article analyzes some advice for quality of life published in a media vehicle. It presents the section 'Equilíbrio' of 'Folha de São Paulo' newspaper, focusing on its editorial proposal, on the topics and texts published by his team and on the readers' comments in the section. Firstly, we will present the organization of this section in the newspaper. Secondly, we will analyze the content of 'Equilíbrio', considering the categories derived from the analysis of the material, covering six months of publication. Finally, we will make some reflections on the operation of this media vehicle in the construction of bio-identities. Key words: Advisors. Bio-identities. Quality of life.

Consejeros mediaticos: el "cuaderno equilibrio" del periódico folha de são paulo y sus ponderaciones en la formación del individuo saludable

Resumen: El artículo analiza consejos para la obtención de calidad de vida ofrecidos en un vehículo de la prensa escrita. De tal modo, el trabajo presente el cuaderno Equilibrio de la Folha de São Paulo privilegiando la propuesta editorial, los temas y textos publicados por su equipo y, además, los comentarios de los lectores en el cuaderno. En un primer momento, será presentada la forma con la que este suplemento se constituye. En un segundo momento, se busca analizar el contenido del cuaderno Equilibrio en función de las categorías construidas a partir del material analizado referente a seis meses de publicación. Finalmente, son construidas reflexiones sobre la actuación de este dispositivo mediático en la formación de bioidentidades.

Palabras-clave: Consejeros. Bioidentidades. Calidad de vida.

Movimento, Porto Alegre, v. 16, n. 04, p. 117-134, outubro/dezembro de 2010. 


\section{REFERÊNCIAS}

BARDIN, Laurence. Análise de conteúdo. Lisboa: Edições 70, 1977.

BAUMAN, Z. Globalização: as conseqüências humanas. Rio de Janeiro: Jorge Zahar, 1999

Modernidade líquida. Rio de Janeiro: Jorge Zahar, 2001.

BOLTANSKI, L. As classes sociais e o corpo. 4. ed. Rio de Janeiro: Graal, 2007.

FOLHA DE SÃO PAULO. Equilíbrio. (suplemento semanal), outubro de 2006 a março de 2007.

FRIDMAN, L.C. Vertigens pós-modernas: configurações institucionais contemporâneas. Rio de Janeiro: Relume Dumará, 2000.

GALIMBERTI, U. I vizi capitali e i nuovi vizi. Milano: Feltrinelli, 2003.

II corpo. 13. ed. Milano: Feltrinelli, 2003a.

GIDDENS, A. As conseqüências da modernidade. São Paulo: Ed. Unesp, 1991.

Modernidade e identidade. Rio de Janeiro: Jorge Zahar, 2002.

ORTEGA, F. Biopolíticas da saúde: reflexões a partir de Michel Foucault, Agnes Heller e Hannah Arendt. Interface - Comunic., Saúde, Educ. vol. 8, n. 14, p. 920, set. 2003/ fev. 2004.

Práticas de ascese corporal e constituição de bioidentidades. Cadernos Saúde Coletiva, Rio de Janeiro, 11, n. 1, p. 59-77, 2003.

Recebido em: 13.09.2010

Aprovado em: 18.10.2010

Movimento, Porto Alegre, v. 16, n. 04, p. 117-134, outubro/dezembro de 2010. 